\title{
Reading images for telling narratives \\ an analysis of the Discursive Operations made with a story-telling game
}

\author{
Marina L. P. Mota, \\ Silvio B. Campello, \\ Angélica Porto C. de Souza
}

\section{INTRODUCTION}

Initiatives that inspire the development of children's language skills appear more and more these days. Within the schooling systems these skills may be conceived as a System of Language Acquisition Activity.

At an institutional level, we may name the Programa Manuel Bandeira de Formação de Leitores (PMBFL) of Recife, PE, as one of these initiatives. The PMBFL has selected stories, which were made and illustrated by students, to be published through its editorial line. There is also the project Nas Ondas da Leitura that is part of the Recife Literacy Program (ProLer). The Program offers all the pedagogical support to stimulate the engagement on reading and writing activities, having also a line that publishes students' best stories.

According to the Ministry of Education of Brasil, MEC, in the early years of Elementary School the child develops the capacity for representation. This is viewed as indispensable for learning to read, grasping basic mathematical concepts and understanding the reality that surrounds her/himself. This kind of knowledge is therefore assumed as postulates for this period of schooling. Indeed, the development of language allows the child to reconstruct her/his actions by memory and to describe them. It also makes possible to plan actions. All necessary skills to the level of learning expected for this age.

It is in this context that the research Atividades de Leitura nas Escolas (Reading Activities at Schools) appears. The objective of the research team had been originally set as to map the systems of reading activities at school and is currently pursuing the development of artifacts and protocols to contribute to the writing of fiction narratives at the Elementary School. Considering the school context as a complex environment, which is affected by several social factors, it was decided to use analytical instruments that might inform about both design requirements and usability levels. The Activity Theory (AT) (Leont'eL, 1981; Engeström, 1987) 
was chosen as such a methodological instrument. The AT is based on Vygotsky's Sociocultural Psychology principles and has been used in the Design field for the past 25 years or so, mainly in the HCI field. AT suggests that, among others things, understanding the system of activities in which an artifact will be later introduced is fundamental for the correct establishment of the design requirements.

Initially, the research selected 3 public municipal schools and identified the Reading Activity Systems in groups of different ages. In this way, the components of these systems - such as the subjects, the main artifacts used, the objectives driving the activity, the rules governing it and the division of labor among the subjects - were identified. At that early stage of the research, the greatest insight came on realizing the real objective of the Reading Activity within the schooling system. Instead of students practicing to read children's books on their own, having the book as a central artifact, we found a set of pedagogical actions happening around those books. Teachers conceived their reading activities as a starting point to develop a set of pedagogical actions aiming specific outcomes. Nothing more according to the theory since at an AT perspective the human actions are not directed to the artifact itself but to the objective associated with its use.

The second required conclusion was that other activities of language acquisition have few or none supporting artifacts, contrasting with the fair amount of titles of children's books for reading. In fact, it was noticed a lack of pedagogical tools for language skills such as fictional writing. This reality suggested the opportunity to research and act in the Writing Activity Systems instead of what was initially designed. The research team, then, designed a game board and a deck of cards for fictional writing and used it to produce children's books written and illustrated by the own students. The game is very simple, consisting of a board figuring 12 sequential places and a deck of 46 cards representing characters, objects, scenarios and actions.

On this article we extended the text published in the Proceedings of the 8th International Information Design Congress (CIDI 2017), adding new information collected after its submission to the event. In addition, there is also a more detailed description of the design process of the board game and the deck of cards. Finally, an analysis of the sentences created by the children while interpreting the images of the cards was performed, resulting in 4 discursive operations proposed.

\section{INFORMATION DESIGN (ID) AND EDUCATION}

Currently, in a World overwhelmed by data and all kind of information, there is a need for organization and orientation in order to the messages to be understandable and well used by people. On the education arena it is sometimes 
crucial. The configuration of a pedagogical artifact has impacts on the way it is perceived, managed and interacted, facilitating or obstructing the achievement of learning outcomes. This is part of the task the field of Information Design has when dealing with the school environment.

Bonsiepe (2011) sustains that the Information Design is based on the concepts of data, information and knowledge, where the primary data (raw data), the elaborated data (information) and the validated information (knowledge) exist. According to the author, in order to transform data into knowledge, the information must be well structured to be understood by the users who share its meaning. However, one may argue that simply decoding the information does not lead necessary to knowledge as defined by Bonsiepe. In order to occur this transformation, users need to interpret the information and make use of it. In other words, when aiming to achieve certain goals, users need to turn information into actions. Therefore, the way information is designed may be crucial because its configuration interferes in the way information is perceived and interpreted, allowing or hindering a more efficient action and consequently satisfying or not a need.

The same author also states that in the future ID can become an important and autonomous field, especially since it is also connected to education. Along this trend, Coutinho and Lopes (2011) discuss two aspects: the first regards the Design's main concern of solving problems applied to mediating learning artifacts; while the second refers to its epistemological and methodological conception as a way of knowing, deeply related to the individuals development process.

These issues suggest the relevance of studying the role of ID within the educational context, enhancing the relation between information designers and educators. Among several examples of an interesting use of information design as a mediating learning artifact inside the educational context we may point out one observed by the research team in the J.P.G. Municipal School, in Recife, Brazil. The teacher have just read the book "The Little King and the Royal Park" along with the students, holding the book on her hands. The book deals with the importance of respecting the differences between people and also about real and fake feelings, issues that the teacher explored with the class while reading. At the end, she handed out small paper crowns set as bracelets around their arms and sent them back to their classrooms. With this simple device, produced by whatever means she had, she increased the chances of getting the children to retell the story whenever someone asked them why they were wearing a crown as a bracelet in their fists. 

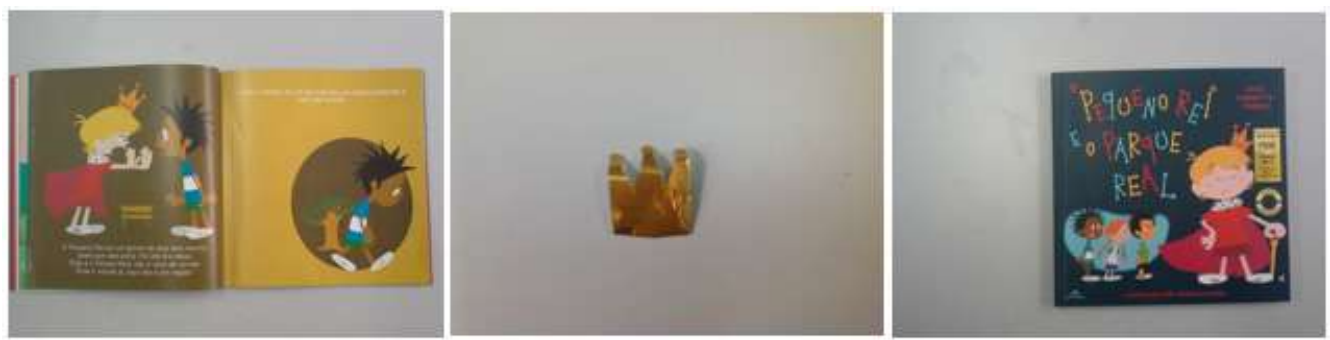

Figure 1: The book The Little King and the Royal Park and the crown bracelet produced by the teacher (research documentation archives).

\section{THE NARRATIVES PROCESS}

People are always telling stories and to do so they use the language as an instrument to communicate with each other, to express themselves or to report information.

Eisner (2005) states that all stories are an account of events specifically arranged in a way to be told. Every story has a structure. They have a beginning, an end, and a line of events placed under a structure that holds them together. It is not important if the story is told through texts, movies or comics. The story may suffer variations in the way it is told, but the basic structure serves as a guide, providing certain control. Although they may vary in many details, the basic principles of a narrative are often the same, whether it is told orally or visually.

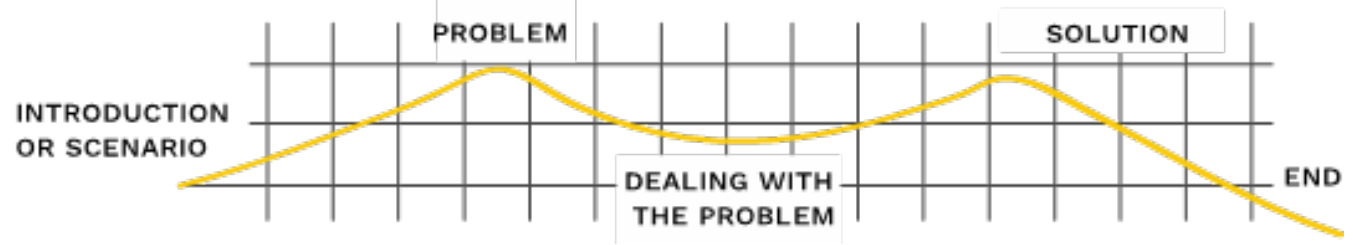

Figure 2: Structure of a story (Adapted Eisner, 2005).

Still according to Eisner (2005), there are different ways for telling stories, but fundamentally only two exist: by words (oral or written) and by images, which are often used in combination. It is likely to mentally visualize images when reading and it is also common to produce texts from contemplating images, creating a cognitive circuit that cannot absolutely separate these experiences (Gamba, 2013). 
These basic elements of a narrative are often present in a variety of artifacts and situations. They may be found in Movies, TV Series, Picture Books, Comic Books or even in Analogical or Digital Games, where the user acts as narrator by "controlling the history".

\section{ACTIVITY THEORY (AT)}

The Activity Theory (AT) has roots dating back to the eighteenth and nineteenth centuries, although nowadays the most discussed version comes from the soviet historical-cultural psychology founded by Vygotsky and carried out by his followers Leont'ev and Luria (Kuutti, 1996). AT itself is not a methodology. Kuutti (1996) states that it is a philosophical framework that serves to study different forms of human praxis as a process of development, considering individual and social levels as interconnected.

Building on the ideas of Leont'ev about human activities and based on Wertsch (1981), Kaptelinin and Nardi (2006) have proposed these basic principles: (1) object orientation, that is, subjects interact with artifacts (tangible or not) in order to satisfy their needs; (2) activity hierarchical structure, which assumes that the Activity is formed by Actions that, in turn, is formed by Operations. The Activity is linked to a Motive, the Actions to the Achievement of Goals, and the Operations to the Conditions; (3) mediation, that is, the need that orients subjects toward the object of activity is satisfied through mediating artifacts that may be material (hammers, knives, etc.) or immaterial tools (concepts, ideas, etc.); (4) internalization and externalization, in the first process, subjects appropriate information and in the second, produce information; (5) development, because to understand how the object of the activity has being transformed through time contributes to understand its current state.

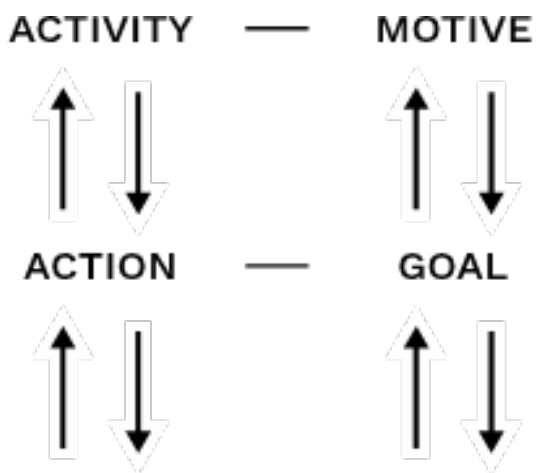

\section{OPERATION - CONDITION}

Figure 3: Activity Hierarchical Structure (Adapted Kuutti, 1996). 
The relationship between the subject and the object of the activity is not that simple because human activity is not a sole individual outcome. It is surrounded by a social superstructure that gives it meaning and purpose. Most activity involve different artifacts made in so many other activities that make it practically impossible to cover every detail. Human activity always occurs within a community, driven by a certain division of labor and by certain rules (Engeström, 1987).

\section{TOOLS}

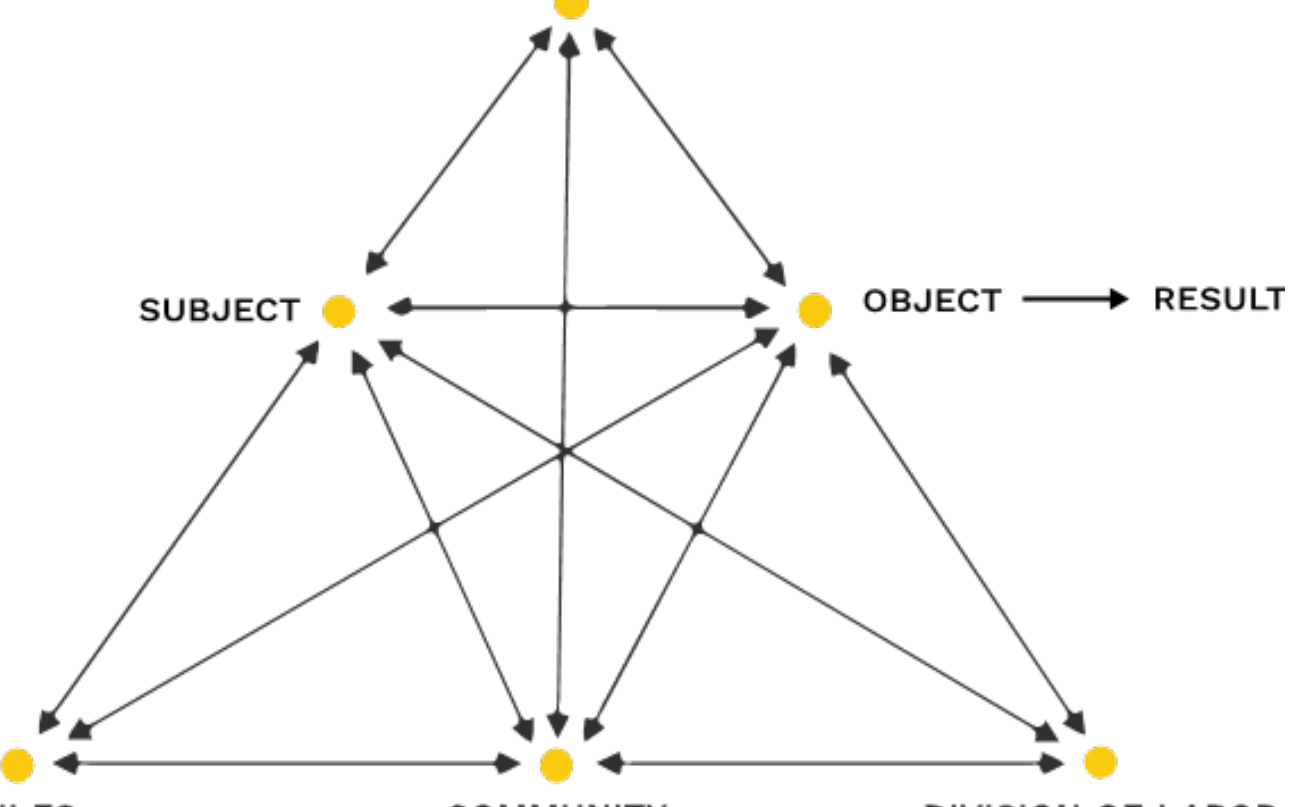

RULES

COMMUNITY

DIVISION OF LABOR

Figure 4: Engeström Activity System (Adapted Engeström, 1987).

Thus, in addition to the subject and the object, a third main component is added: the community (which shares a common object). Then, two new relationships are formed: subject and community and community and object (Kuutti, 1996). The relationship between subject and object is mediated by the tools, the relationship between subject and community is mediated by social rules and the relationship between object and community is mediated by the division of labor. A tool (both material and immaterial) can be anything used in pursuing the object. The rules may be explicit or implicit and cover norms, conventions and social relations within the community. The division of labor refers to the implicit or explicit organization of the group in the process of transforming the object into result (Kuutti, 1996). 


\section{THE STUDY: METHODOLOGY, GAME DESIGN, ANALYSIS AND RESULTS}

\section{Methodology}

This study was conducted at J.P.G. Municipal School, an elementary public school located in Recife, Brasil, during 3 phases. In the first one, during the first semester of 2016, 9 students took part. In the following semester of 2016 a second one took place with the first 9 students plus 3 new ones. All the students were enrolled in the 5th school year, which age group within the system is of 11 years old.

The third phase occurred in the first semester of 2017 with another group of participants. These include 1 teacher and 20 students of the 4th school year, which age group is of 10 years old. During all 3 phases, the school librarian, who was responsible for several Reading Activities at that school and actually introduced us to the children, was present and helped in addressing to them. The study consisted in the use of an artifact for creating fictional narratives (a board game and a deck of cards) followed by a workshop to illustrate the stories made. After that, the stories were published as children's books. At each phase there were small modifications in the protocol that will be described later. Observations and semi-structured interviews were performed after each study and the stories analyzed.

The data were analyzed based on Leont'ev's (1981) Activity Theory, focusing on the principle of Hierarchical Structure of Activity in order to understand the motive drawing the activity, the goals each action pursues and the conditions in which the subjects performed the operations. The data was also analyzed through the Engeström's Diagram (Engeström, 1987), which extends the activity to a collective context, making it possible to relate and discuss each component of an activity system.

The game design

\section{The Board}

The game board is very simple, consisting of 2 A3 papers printed in a solid background color, figuring 12 numbered places linked by a path that goes up to bottom. The first version of this board was created in 4 colors: green, red, blue and yellow, with the purpose of making it easy to identify the different groups of students and their stories. Because of managing a large number of students seemed unwise it was decided that 6 people should use each board at most. The numbered places on the board's path as well as the path itself serve to indicate the 
sequence and flow of the story.

Each one of the 12 places on the board will represent an event within the story. Therefore, it is likely to be turned into a scene of the book. The number of 12 places was established then, thinking on how many pages the printing resources and the research budget would permit.

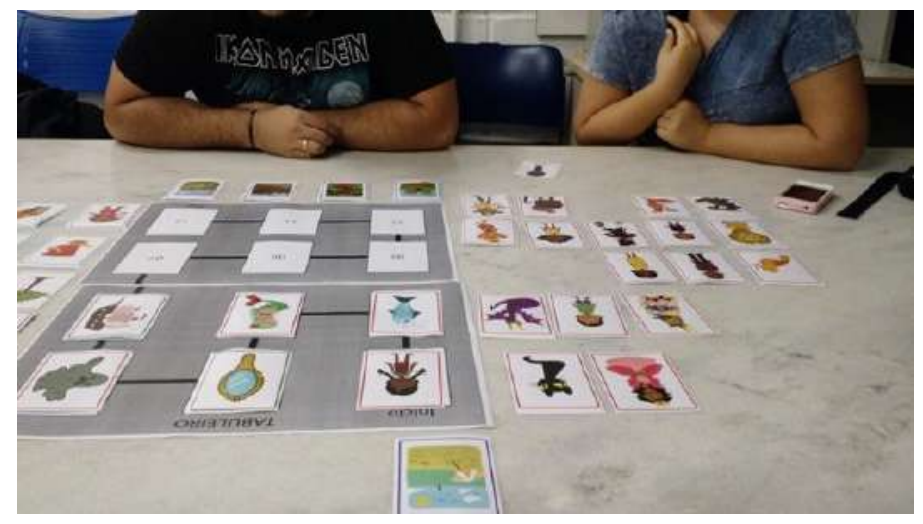

Figure 5: Game prototype being tested by the researchers.

The mechanic is as follows: each player lays down a card chosen from the deck on the next free numbered place and tells a passage of the story, relating it to the card; the next player must do the same, continuing the story already started. At the end, a story is created collectively.
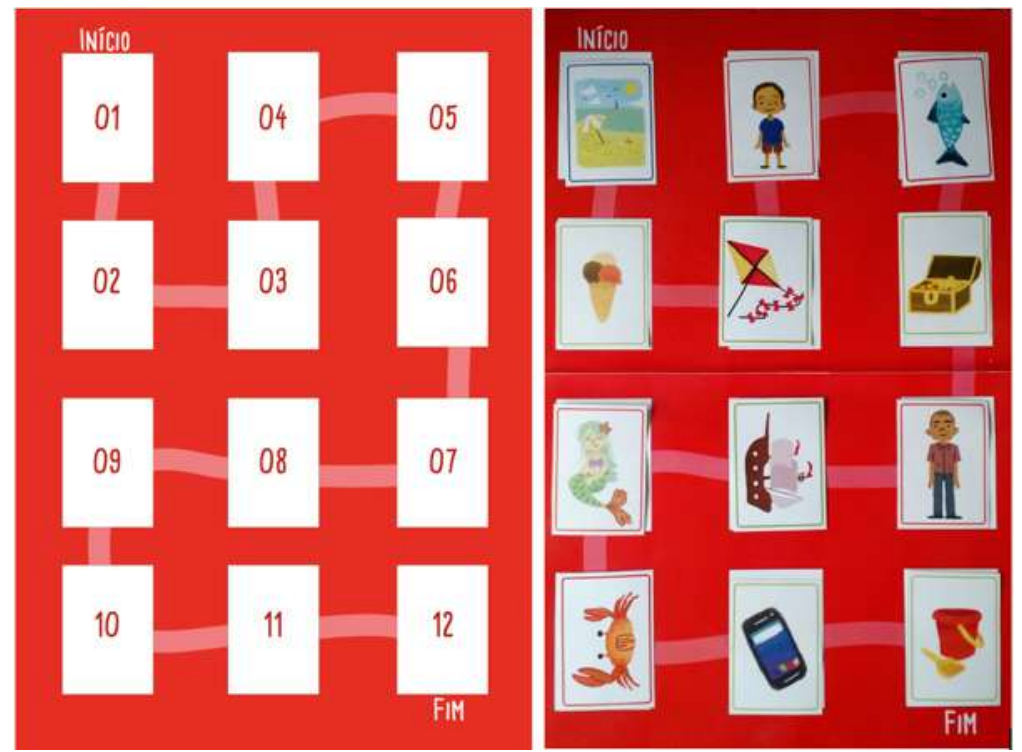

Figure 6: Board's first version design (left) and board with the applied cards (right)

After the first phase, the board was redesigned because some students, and 
even the librarian, mistook the flow of the story when reading the scenes. It was probably because the path did not always represent the flow from left to right. In an age that all are being trained on reading Portuguese it was not a exactly a surprise. In addition, the places were all in rectangular shapes and laid out vertically while some of the cards were better arranged in the horizontal orientation. In the second version of the board the places were drawn as circles to indicate where the card should be inserted, regardless being vertical or horizontal oriented. The reading flow of the path has also been adjusted, but it did not yet fully comprise the traditional Western reading system, and can still be improved.

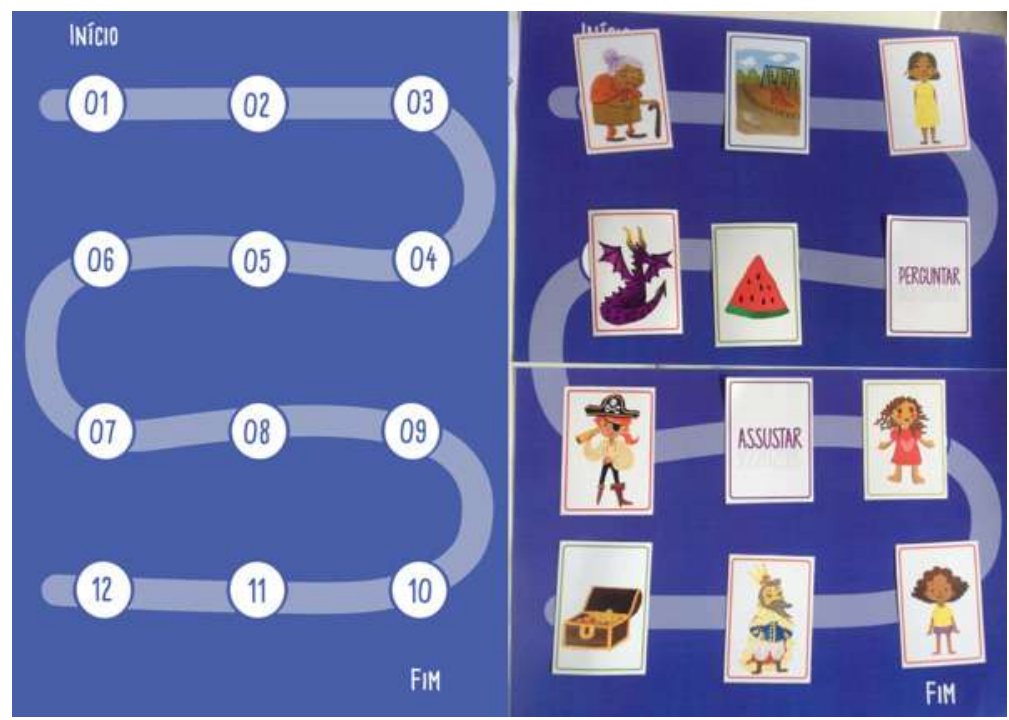

Figure 7: Board's second version design (left) and board with the applied cards (right).

\section{The Deck of Cards}

According to Reis and Lopes (1988) to analyze a narrative structure, at the story plane, one must consider the actions, the characters, the locations and their interdependence relations. One must also take into account their specific structural weight for the narrative (the decisive actions for the intrigue flow, the subsidiary actions of an indicial nature, the distinction between the main characters, the minor characters and the extras, the connections between characters and locations, etc.).

Gancho (2002) corroborates with Reis and Lopes' view of the narrative structure and adds two new elements, which according to her are essential for 
creating a story. She basically states that without events (actions) one cannot tell a story, pointing out that the characters are the ones who live these events, in times and determined locations. Finally, she preconizes that the presence of a narrator is necessary - a fundamental element to the narrative - because it is who transmits the story, mediating the relationship between the narrative and the listener, reader or viewer (Gancho, 2002).

The common categories of narrative structure between these authors are "event/action", "character" and "location". They suggest that in any kind of story "something happens to someone, somewhere". There is still the role of objects as a fundamental element to concretize the subject's actions. Kaptelinin and Nardi (2006) based on Leont'ev's ideas, say that the interaction of the subject with the world is structured and organized around objects, which have attached to them an objective purpose and a potential to satisfy human needs given that the subject acts in accordance. Objects may be tangible (like a bull's eye on a target) or intangible things (like "I want to be a brain surgeon").

Considering all those elements that may compose narratives or are related to them, a deck of 46 cards was developed. This deck contains 20 figures of characters, 04 of scenarios, 16 of objects and 06 verbs. The 2 others elements of Gancho (2002) are satisfied by the players that take in turn the role of narrating a story and realize its time. In our case, aiming to produce children's literature, the fantastic background attempted to grasp in the cards may set time at some undefined point.

The design of the cards was elaborated based on 2 strategies. Initially, a collective structured interview was conducted aiming at a better understanding of personal interests of each child in regard to hobbies, activities and wishes. Table 1 shows the questions made and the answers quantified by the number of occurrence:

\begin{tabular}{|l|l|l|l|l|l|}
\hline \multicolumn{2}{|l|}{$\begin{array}{l}\text { What do you like to } \\
\text { play? (Playfulness) }\end{array}$} & $\begin{array}{l}\text { What did you do on } \\
\text { your last vacation? } \\
\text { (Concrete fact) }\end{array}$ & \multicolumn{2}{l|}{$\begin{array}{l}\text { What would you like to get for } \\
\text { Christmas or a birthday gift? (Wish) }\end{array}$} \\
\hline Hide and seek & 3 & Watch Television & 2 & $\begin{array}{l}\text { Smartphone (6 mentioned } \\
\text { the smartphone Moto G 3rd } \\
\text { generation) }\end{array}$ & 9 \\
\hline Bike & 1 & Go to the beach & 7 & Tablet & 2 \\
\hline Kite & 1 & Amusement park & 1 & Skate & 1 \\
\hline Soccer & 8 & Play with ball & 1 & Video game & 3 \\
\hline Tag & 3 & Travel & 1 & Notebook & 1 \\
\hline & & Go for a walk & 1 & Doll & 1 \\
\hline & & & & Bike & 1 \\
\hline
\end{tabular}

Table 1: Mapping of the student interests. 
The data show live games and outdoor activities most frequently mentioned. Terms such as "football", "tag", "hide and seek" and "beach" are found in all 3 types of questions. On the other hand, technological artifacts were mostly remembered on the wish list. Artifacts such as "tablets", "video games" and "smartphones" seem to be of great importance as objects of desire.

After that, another survey was made about the themes and graphic styles of the most requested books from the school library. The themes and the number of times a book in that category was borrowed is shown in Table 2 below:

\begin{tabular}{|l|l|}
\hline Book themes & Amount \\
\hline Animal & 16 \\
\hline Fantasy & 10 \\
\hline Environment & 04 \\
\hline Body parts & 02 \\
\hline Celebrities (ex: Ronaldinho Gaúcho) & 06 \\
\hline Romance & 02 \\
\hline Routine situations & 03 \\
\hline Sport & 01 \\
\hline Toys & 01 \\
\hline Religion & 01 \\
\hline Regional & 01 \\
\hline Music & 01 \\
\hline Transportation & 01 \\
\hline
\end{tabular}

Table 2: The themes and their frequency identified among the most requested library books.

The data displays a noticeable predominance of "animals" and "fantasy" themes. In several of these children's books, the animal is considered the main character, sometimes associated with human characteristics and humanmade environments. An example is shown on the figure 8 , in which the main character is a fox that steals the chickens and goes to typical human environments, like living rooms with fireplaces. 

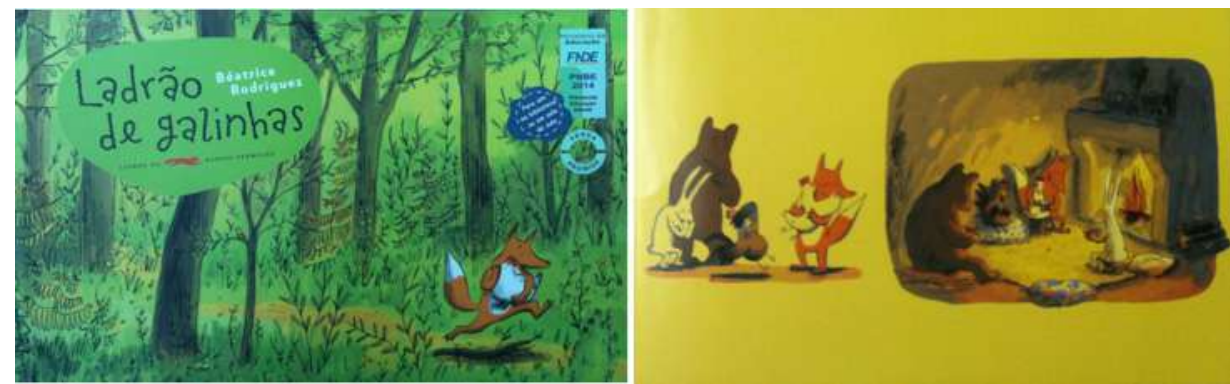

Figure 8: Record of the book "The thief of chickens" by Béatrice Rodrigues. Book of the PNBE 2014 collection.

The design of the cards and their color palette was also conceived taking into account the analyzed books. The design of illustrations is intentionally childish and the palette contemplates several vibrant colors, providing a playful aspect to the deck of cards. In addition to the 46 original cards, another one illustrating a microphone was latter introduced aiming at organizing the turn-taking, suggesting that only the player that holds the card may speak.

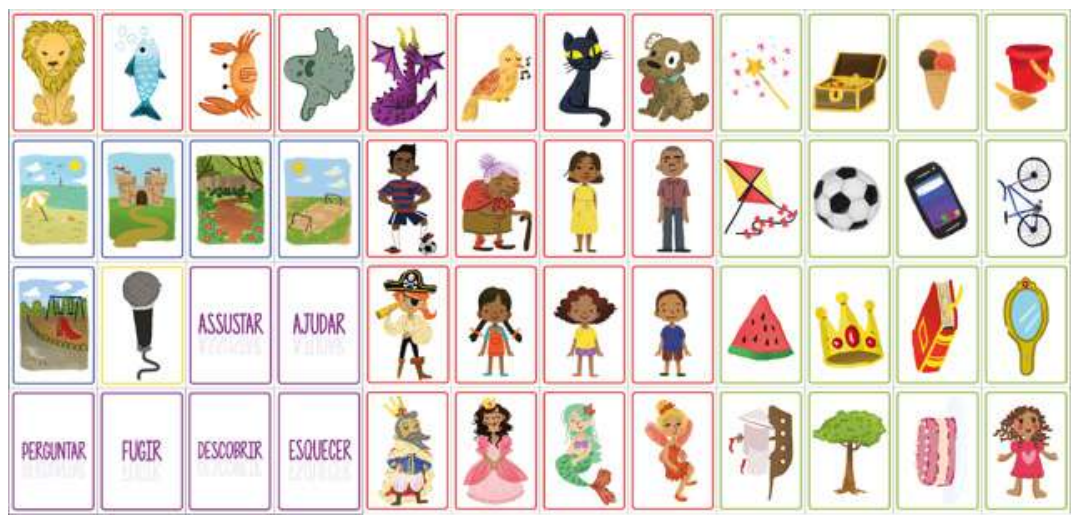

Figure 9: Complete deck of cards: characters (red outline), objects (green outline), scenarios (blue outline) and actions (purple outline).

Since the stories were orally told, transcription sheets were designed to record them. During the first and second phases of the study, a research member mediated the activity on each group, including writing the stories down to the transcription sheets. However, at the third phase, children became the writers, making thus the activity autonomous, eliminating the researcher's active role as an editor. This however, raised an issue of better designing these transcription 
sheets, making them more suitable for this type of user. One of the possibilities is to consider in what type of papers students use to write down their school activities.

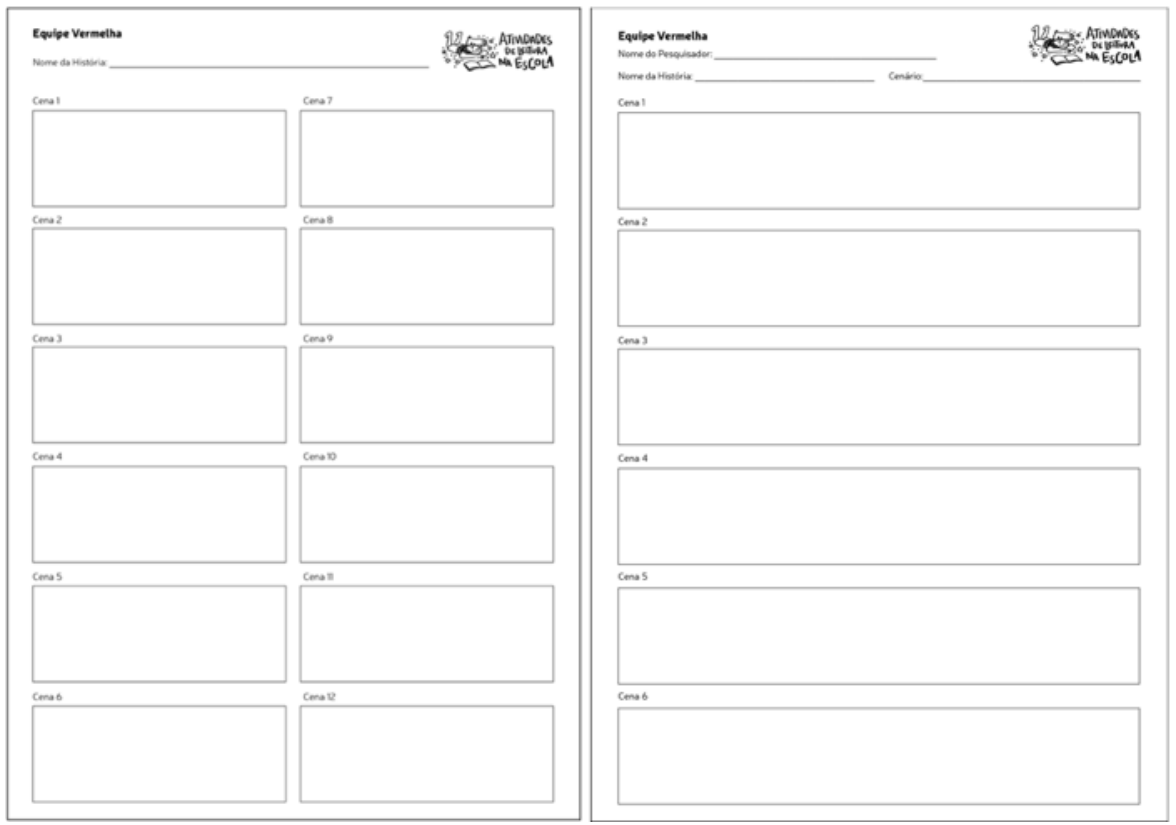

Figure 10: Examples of the transcription sheet used to record the narrative.

\section{The board game in the educational context}

The data collected in the first phase refer to two groups of players: yellow and red groups. The yellow group created the story "The lost girl in the forest" and the red group created the story "A wonderful day at the beach".

In the second phase the data refer to another two groups: red and blue. The red group created the story "The Adventures of Arthur" and the blue group created the story "The Witch in Disguise". Once again, both the first and second phases were performed with the 5th year classmates of the JPGMS.

The most significant differences between the first and second phases are the introduction of an initial round for testing the game and the addition of the 6 verbs cards, adding the action category to the deck. The purpose of these changes was to make the narrative more structured and dynamic.

The data of the third phase of the study refer to the 3 groups: yellow, green and red. The yellow group created the story "The Children and the Fairy", the green group created the story "The discovery of a book" and the red group created the story "The Best Mother's Day". 
At the third phase there was no initial round, but as the start of the game was unimpeded, many children explored the cards before beginning to play. An important change in the protocol of this phase is related to the researchers' role: they only observed the activity because the children themselves became the editors. The purpose of this change was to make the activity autonomous in a way that it could be replicated in other schools.

The following table summarizes the main characteristics of each phase of the study:

\begin{tabular}{|l|l|l|l|}
\hline & First phase (2016.1) & Second phase (2016.2) & Third phase (2017.1) \\
\hline Subjects & $\begin{array}{l}\text { 9 students from the } \\
\text { 5th year Elementary } \\
\text { School }\end{array}$ & $\begin{array}{l}\text { 12 students from the } \\
\text { 5th year Elementary } \\
\text { School }\end{array}$ & $\begin{array}{l}\text { 15 students from the } \\
\text { 4th year Elementary } \\
\text { School }\end{array}$ \\
\hline Board version & 1'a version & 2-a version & 2a version \\
\hline Used cards & $\begin{array}{l}\text { Objects, scenarios, e } \\
\text { characters. }\end{array}$ & $\begin{array}{l}\text { Objects, scenarios, } \\
\text { characters and actions. }\end{array}$ & $\begin{array}{l}\text { Objects, scenarios, } \\
\text { characters and } \\
\text { actions. }\end{array}$ \\
\hline Story editor & Researcher & Researcher & Students \\
\hline $\begin{array}{l}\text { Inicial test } \\
\text { round }\end{array}$ & No & Yes & No \\
\hline $\begin{array}{l}\text { Setting the } \\
\text { game }\end{array}$ & All cards face up. & $\begin{array}{l}\text { Face-up cards } \\
\text { separated by category } \\
\text { (one stack of cards for } \\
\text { category). }\end{array}$ & $\begin{array}{l}\text { Random, each group } \\
\text { decided how to start } \\
\text { the game. }\end{array}$ \\
\hline $\begin{array}{l}\text { Stories } \\
\text { created }\end{array}$ & $\begin{array}{l}\text { The lost girl in the } \\
\text { forest | A wonderful } \\
\text { day at the beach }\end{array}$ & $\begin{array}{l}\text { The Adventures of } \\
\text { Arthur I The Witch in } \\
\text { Disguise }\end{array}$ & $\begin{array}{l}\text { The children and the } \\
\text { fairy I The discovery } \\
\text { of a book I The Best } \\
\text { Mother's Day }\end{array}$ \\
\hline
\end{tabular}

Table 3: Summary of the research protocol for each phase of the study.

Records of the stories, both visual (cards placed on the board) and verbal (the story narrated orally and transcribed in text by the researchers or students) may be seen in the following figures: 


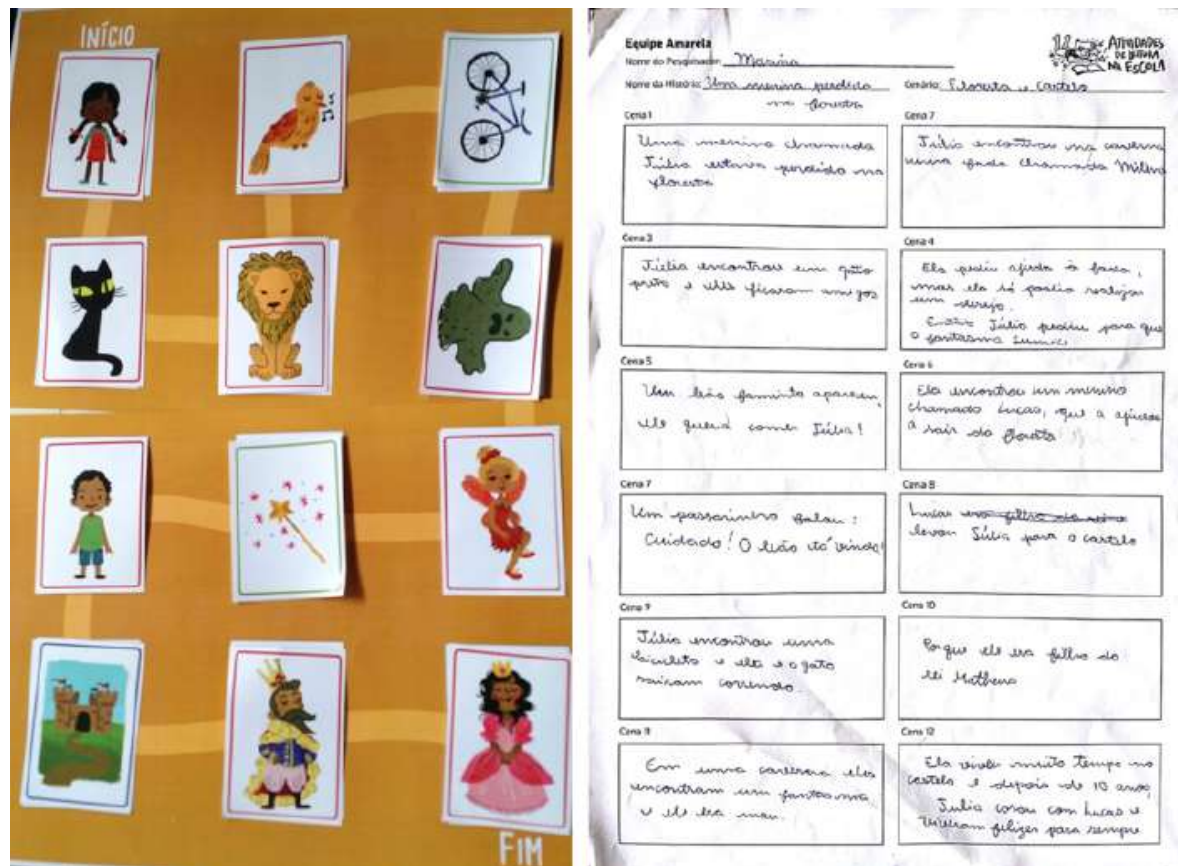

Figure 11: Visual and textual record of "The lost girl in the forest" story.
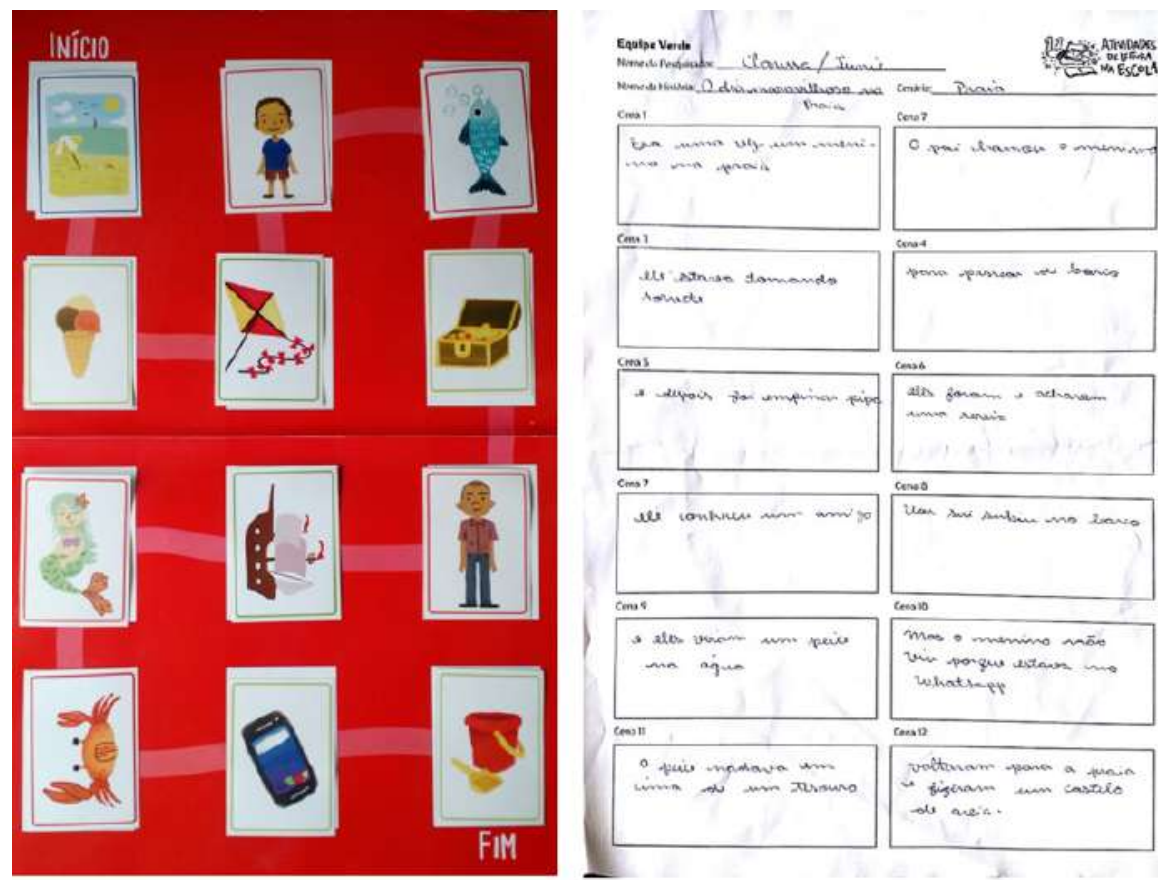

Figure 12: Visual and textual record of "A wonderful day at the beach" story. 

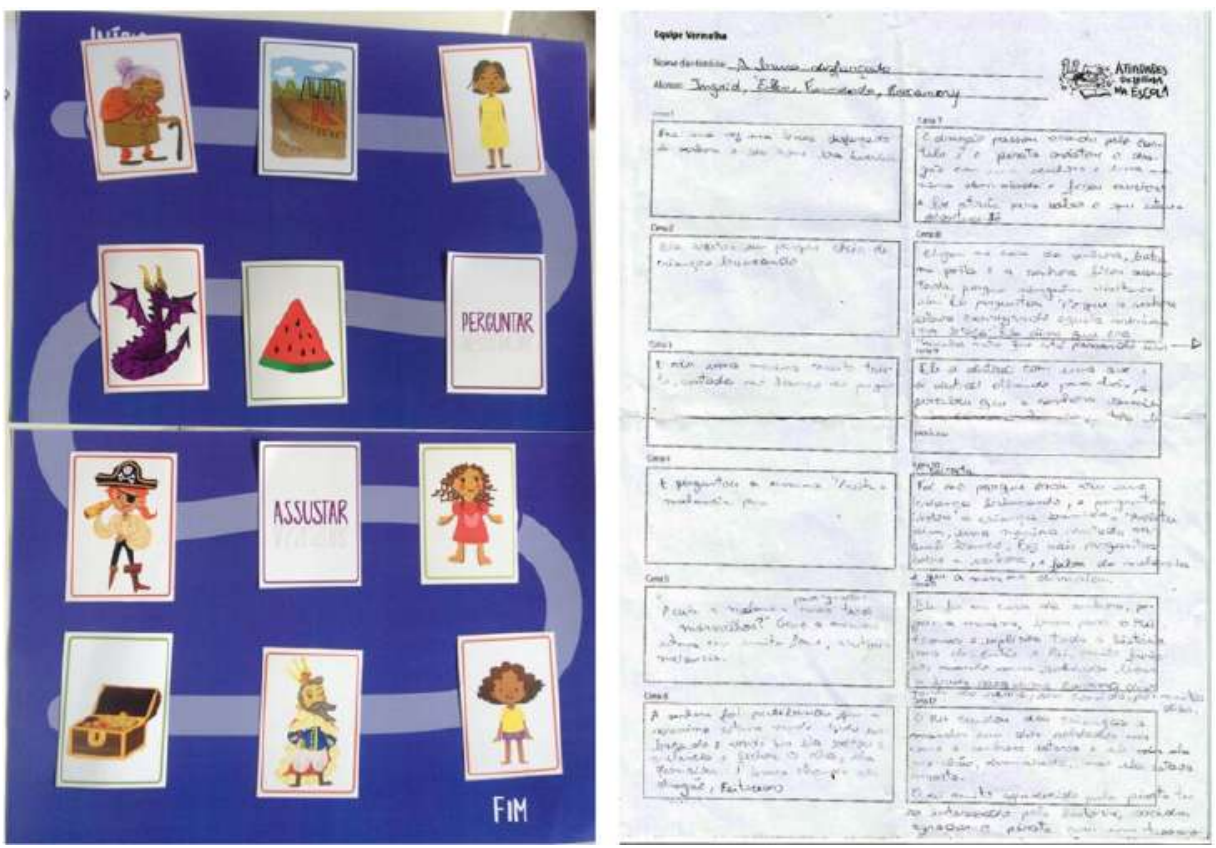

Figure 13: Visual and textual record of "The witch in disguise" story.
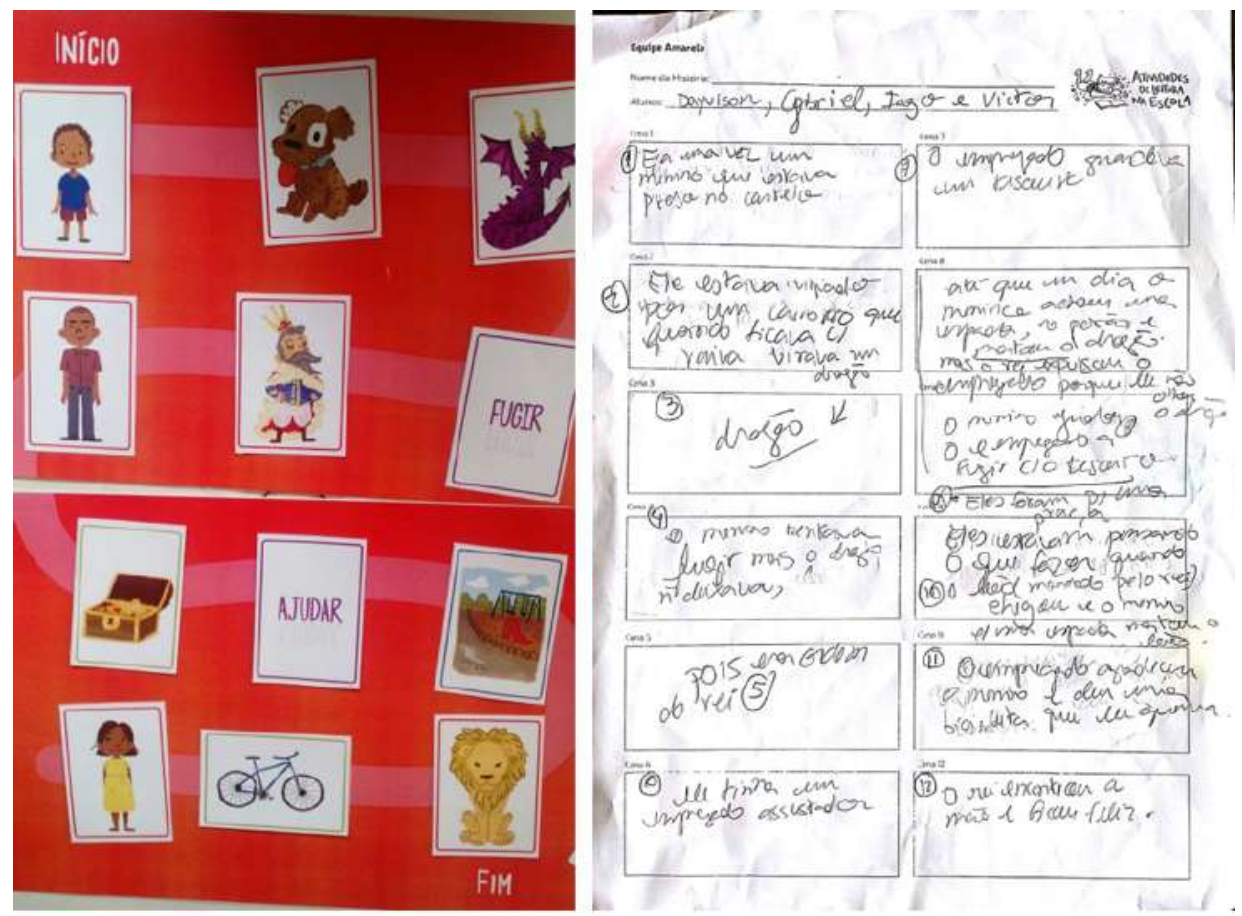

Figure 14: Visual and verbal record of "The adventures of Arthur" story. 


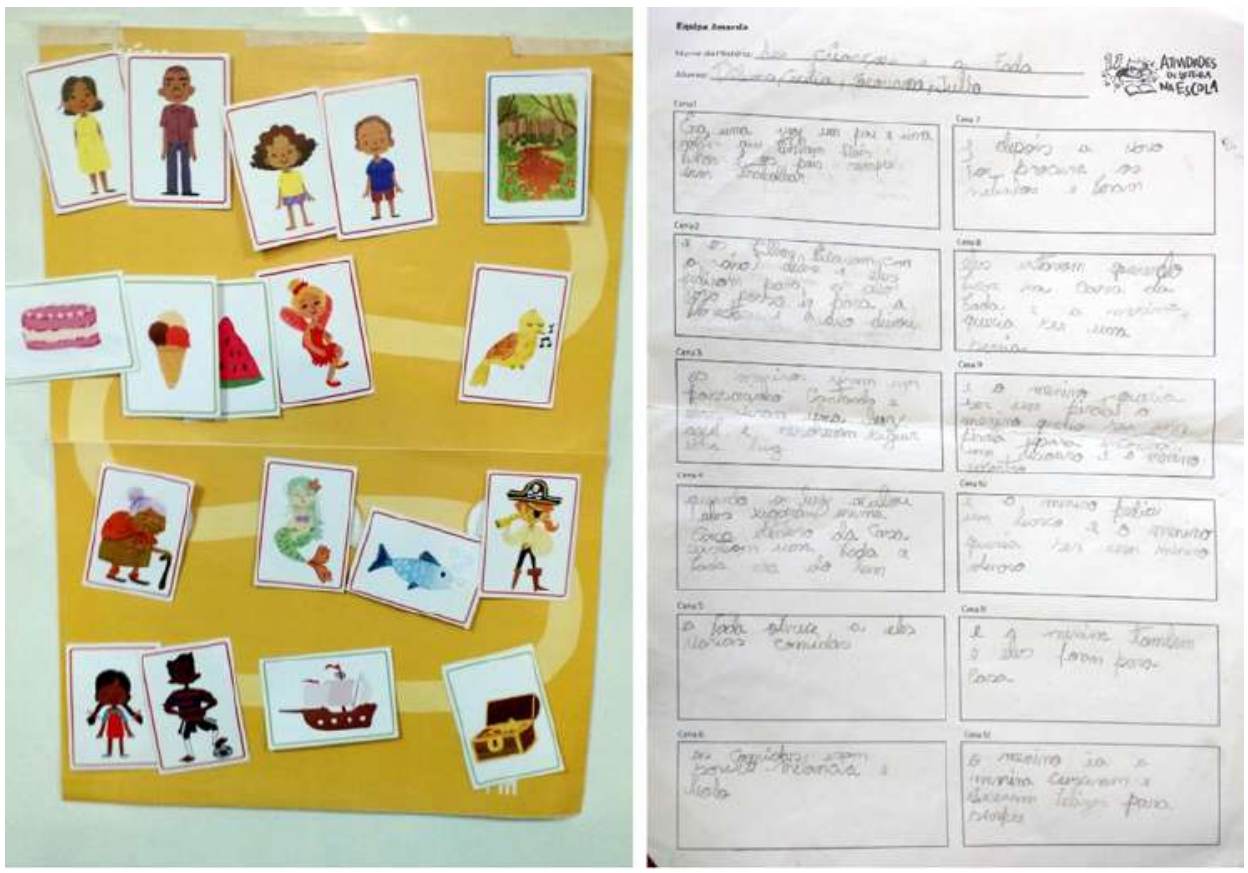

Figure 15: Visual and verbal record of "The children and the fairy" story.
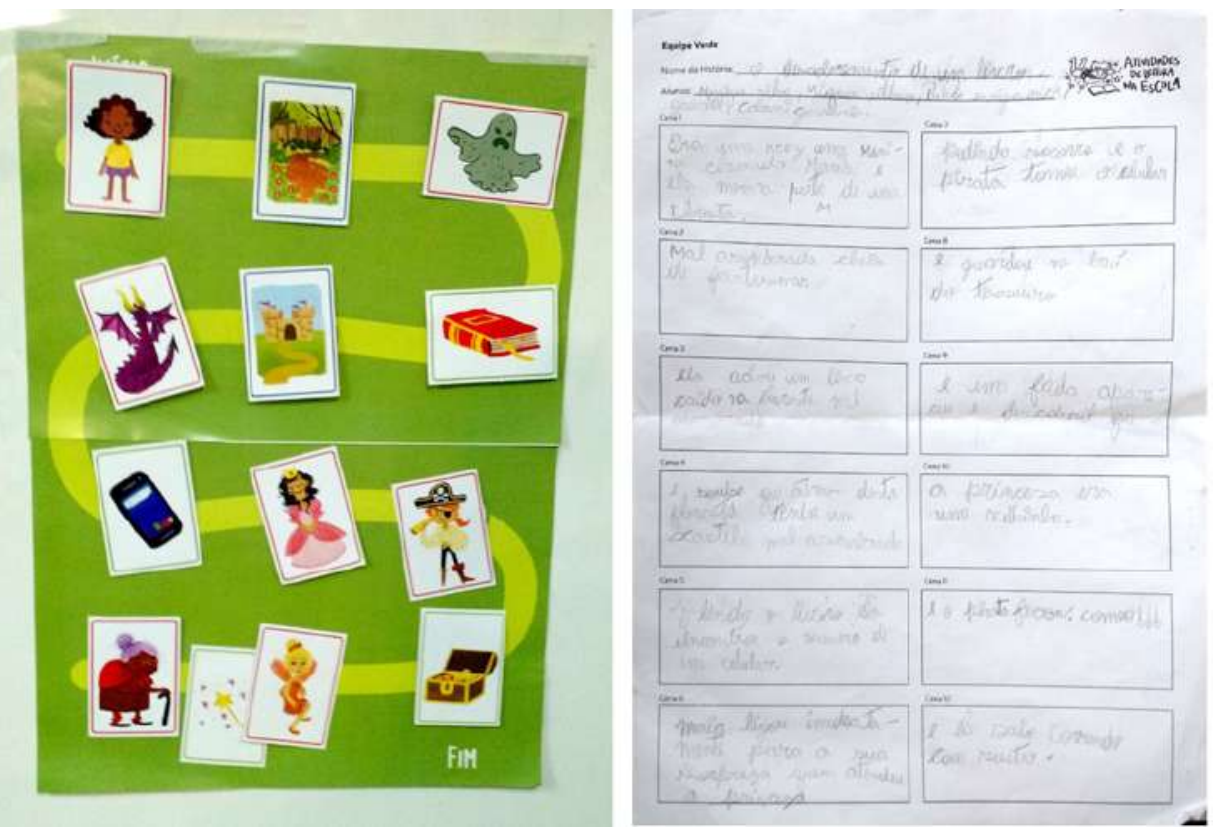

Figure 16: Visual and verbal record of "The discovery of a book" story. 

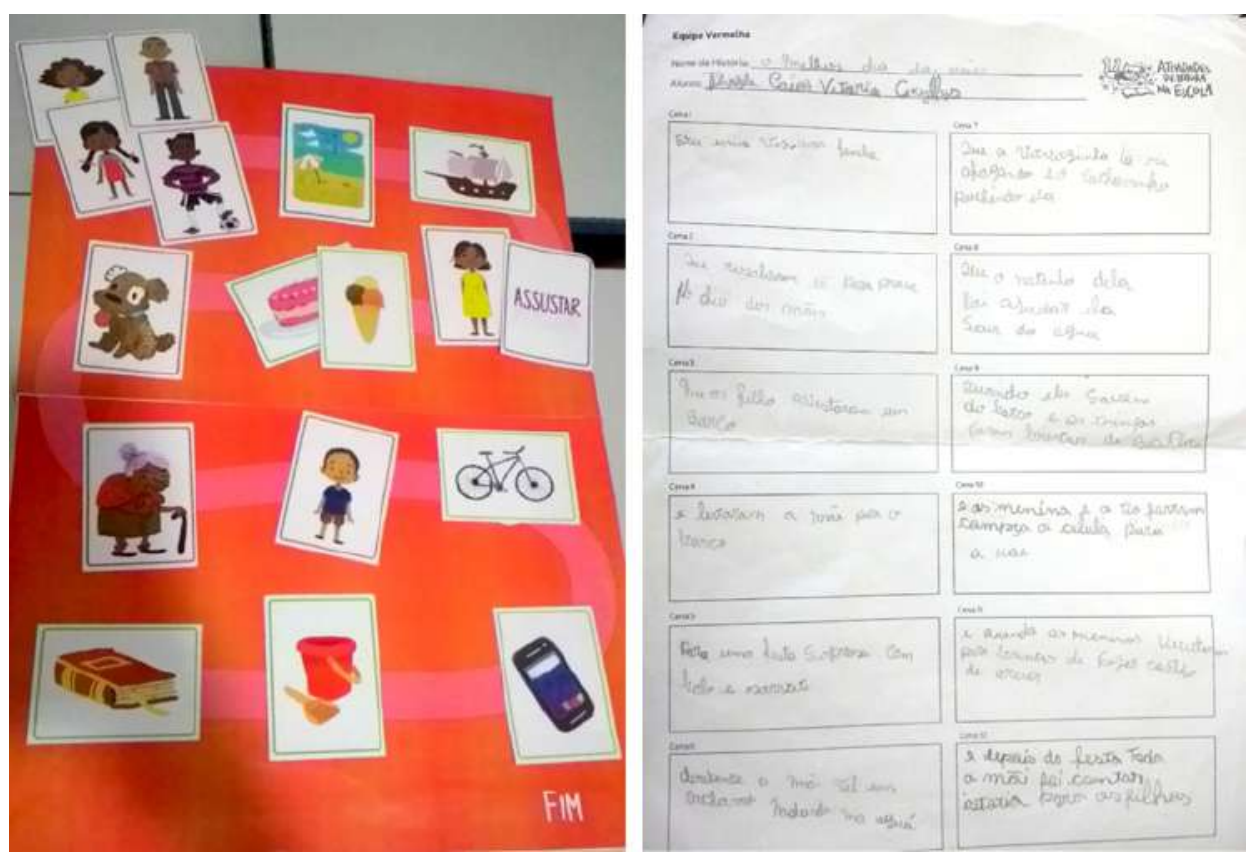

Figure 17: Visual and verbal record of "The best Mother's Day" story.

Analysis and Results

Analysis of the activity at individual level

It was possible to understand the process of using the game to create a story, from its conception until the small details, basing the analysis on the transcribed story, on the observations made during the activity and on the semi-structured interviews performed after it. Using the principle of hierarchy comprised in the activity, action and operation triad, the activity was separated into these 3 hierarchical levels as can be seen in the figure 18 below: 


\begin{tabular}{|c|c|c|}
\hline ACTIVITY & ACTION & OPERATION \\
\hline \multirow[t]{6}{*}{$\begin{array}{l}\text { Creating stories } \\
\text { for a children's book }\end{array}$} & $\begin{array}{l}\text { To understand } \\
\text { the game rules }\end{array}$ & $\begin{array}{l}\text { - To listen to the researcher introducing the rules } \\
\text { - To ask in case of doubts }\end{array}$ \\
\hline & To choose a card & $\begin{array}{l}\text { - To look for the available game cards } \\
\text { - To look at the cards already placed on the board } \\
\text { - To select one card from the available game cards }\end{array}$ \\
\hline & $\begin{array}{l}\text { To construct a narrative } \\
\text { using the figures } \\
\text { displayed on the cards }\end{array}$ & $\begin{array}{l}\text { - To look at the card } \\
\text { - To speak out the thoughts } \\
\text { - To look around } \\
\text { - to look at the other cards on the board } \\
\text { - To listen to what your colleagues say }\end{array}$ \\
\hline & & {$\left[\begin{array}{l}\text { To narrate a passage of the story } \\
\text { (1) To narrate using only the figure on the card; } \\
\text { (2) To narrate using the figure on the card and } \\
\text { another element already present in the narrative; } \\
\text { (3) To narrate relating the figure on the card } \\
\text { to one or more elements of the imagination; } \\
\text { (4) To narrate through the association of ideas, } \\
\text { without mentioning the figure on the card. }\end{array}\right.$} \\
\hline & & - To position the card on the board's correct place \\
\hline & To write the narrative & $\begin{array}{l}\text { - To listen to the narrative } \\
\text { - To absorb content } \\
\text { - To write on the transcription paper sheet }\end{array}$ \\
\hline
\end{tabular}

Figure 18: Hierarchical levels of activity (prepared by the author based on Leont'ev, 1981)

The purpose of the activity consisted in collectively creating stories to make children's books. In order for this to happen, specific actions connected to specific goals had to be performed. Each action, in turn, had a set of operations in order to happen.

The first action: to understand the game rules, is crucial. Students must grab that they need to select a card and relate its figure to a story-telling event. In a way that is consistent with the narrative being told.

The action of choosing a card, when happening in the first round, was cause of internal conflict for the children. More than half of them reported that it was the hardest part and one even said, "There was a lot of thought in my head". Another relevant aspect related to this action is the adjustment needed when cards are already set on the board from the previous rounds. The goal then must include associate a next card to the previous ones so the narrative makes sense. 
The action to construct a narrative using the figures on the cards relates to several operations but it is plausible that to narrate a passage of the story has a central role for the activity. We identified that this particular operation may take the form of 4 Discursive Operations and used them as categories for discourse analysis. They are as follow: (1) to narrate using only the figure on the card; (2) to narrate using the figure on the card and another element already present in the narrative; (3) to narrate relating the figure on the card to one or more elements of the imagination; (4) to narrate through the association of ideas, without mentioning the exact figure on the card.

The last action to write the narrative happened only in the third and final phase, when students became the story editors.

\section{Analysis of Discursive Operations}

The first discursive operation, (1) to narrate using only the figure on the card, happened in simpler and direct passages, as did the player who narrated the following sentence when choosing a boat figure: "To go boating" $(\mathrm{C} 08 \mathrm{H} 02)$.

The second discursive operation, (2) to narrate using the figure on the card and another element already present in the narrative, happens when the story has already started. The child chooses the figure and associates it to another one already set on the board. For example, a player seeing the card "king's servant" that was already placed on the board and choosing the treasure card to add, narrates the following passage: "The servant kept a treasure!" (C07H04).

The third discursive operation, (3) to narrate relating the figure on the card to one or more elements of the imagination (not present in the narrative), is associated with the child's imagination. This operation takes the figure displayed on the card, but relates it to external elements. For example, a player selected the lady figure and narrated the following: "Once upon a time there was a witch disguised as a lady and her name was Lucrecia” (C01H03).

That is, she imagined that the figure of the lady could be a witch and introduced that idea into the narrative. Another example was when the player associated the figures of the cake and the ice cream to the context of a party, narrating the following sentence: "For a surprise party with cake and ice cream" (C05H07).

The last discursive operation, (4) to narrate through the association of ideas, without mentioning the figure on the card, is related to the child's ability to interpret. She observes the figure and associates it with some completely different fact or other element, without even quoting the figure itself. It happened with a player that selected the figure of the wand and narrated the following: "Julia asked for help to the fairy Milena, who said that could only grant a single wish" (C08H01). 
That is, the player interpreted the figure of the wand and associated with the action "to grant a single wish". Another case occurred when the player selected the figure of a cell phone and narrated as follow: "But the boy did not see because he was using WhatsApp!" (C11H02)

Here one can see the influence of the contemporary media elements at children's daily lives by relating the cell phone to the instant messaging application "WhatsApp". Another example of interpretation was when a player associated the figure of a queen to the girl in the story, creating a leap on time by telling that she had already aged and married the king's son. This works on the temporality issue, in the question of time within the narrative: "The girl lived for a long time and then, after 10 years, marries Prince Lucas, with whom she lived happily ever after!” (C12H01).

The table below summarizes the analysis by the number of times each Discursive Operation appeared in the narratives:

\begin{tabular}{|l|l|}
\hline (1) To narrate using only the figure on the card & 03 \\
\hline $\begin{array}{l}\text { (2) To narrate using the figure on the card and another element already } \\
\text { present in the narrative }\end{array}$ & 42 \\
\hline $\begin{array}{l}\text { (3) To narrate relating the figure on the card to one or more elements of the } \\
\text { imagination }\end{array}$ & 32 \\
\hline $\begin{array}{l}\text { (4) To narrate through the association of ideas, without mentioning the } \\
\text { figure on the card. }\end{array}$ & 07 \\
\hline
\end{tabular}

Table 4: Frequency of Discursive Operations.

All the quoted characters, objects, scenarios and actions objectified or not into the cards were considered. The actions (verbs) that are naturally associated with a certain word and/or characteristics of these words (adjectives) were not considered as new elements.

An example is "afterwards, he was playing with a kite" which was accounted to the first category. This is the simplest way of thinking. The subject only quotes the figure in a basic action (usually associated with it), without relating it to another element.

The 2 nd and 3rd discursive operations are those with the highest number of occurrences. The first place of the 2 nd can be explained by the fact that the subject naturally associates the figure on the card with something already present in the narrative. In second place appears the 3rd operation, when the player associates the figure on the card to external elements, usually through the child's imagination or something that has been heard and/or seen where the activity is happening. 
The last operation had fewer occurrences, although it is quite interesting. The player does not mention the figure itself or associate it to any element of the narrative or in the deck of cards and interprets the figure. It may refer to actions, as in the "wand" example in which the subject associates to "grant a wish" or even elements of contemporaneity, such as the figure "cell phone" referenced to the WhatsApp application.

\section{Analysis of the collective level}

In order to understand the efficiency of an artifact in a school environment the Engeström Activity System Diagram (1987) was used for the analysis of the collective level. In other words, it was verified how each element of the system relates to each other. The study main insights are described below:
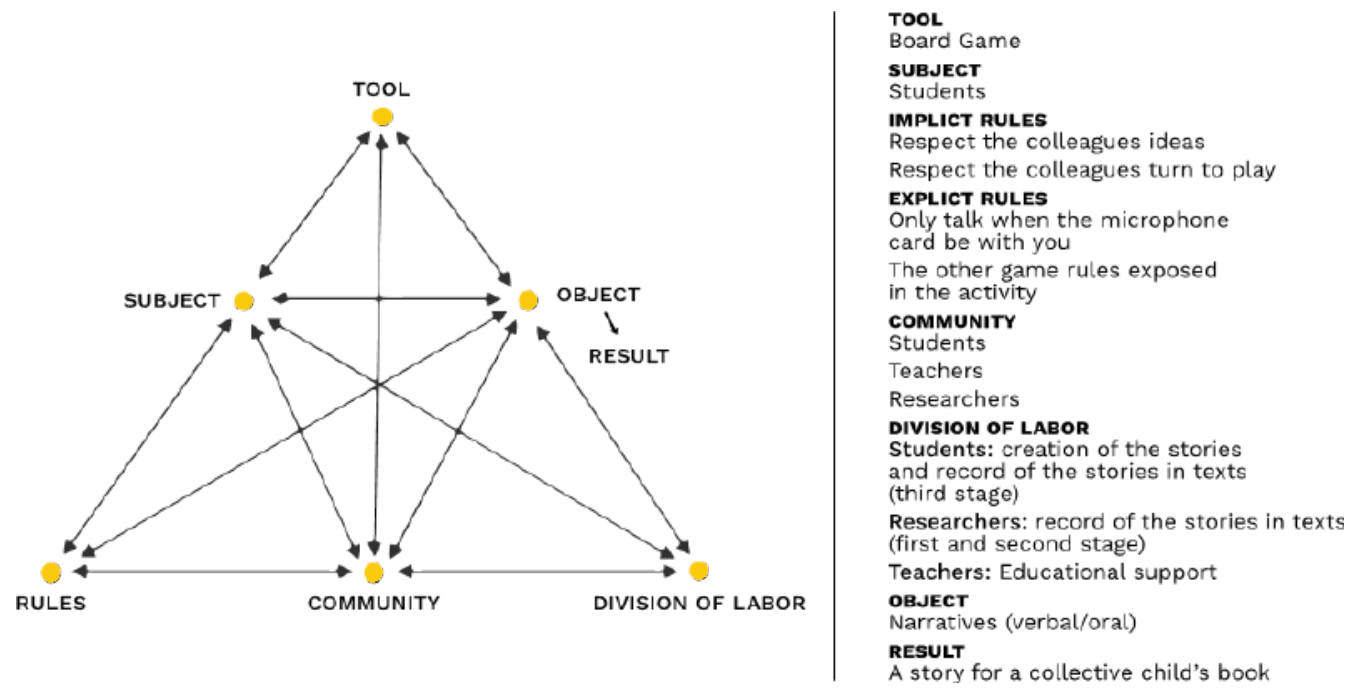

Figure 19: Narrative production activity system (created by the author based on Engeström (1987).

In the first phase of the study, the subjects became curious about the tool because it was a new thing in the school. In the second phase, the students had already used the game and were familiarized to the board, the cards and the idea of collectively producing the story. The new board design (second version), which aimed to clarify the flow of the stories, helped in its reading, but some students and even the teacher were confused sometimes.

In the third phase the players changed, so, as it was the first time they were participating, some students reported that only seeing the finished book they actually understood what the stories would be for. Initially, they dealt with the 
board game and the cards just as an object to play with. They also reported that at first they wanted to copy existing stories, but later as the game was played they understood that the stories needed to be original and that the cards would help suggesting ideas for them. A teacher pointed out this fact when said that even children who have never had contact with textual production could create a story in this way, by choosing the figures, changing their positions, suggesting alternatives, etc. Another fact that drew attention at this phase was the selection of multiple cards (up to four) to express a single idea placing them together on just one of the board's places. The game designers did not foresee this strategy, but it was immediately incorporated into the rules. For example, a player selected the cards displaying the figure of a woman, a man, a boy and a girl and associated them to the idea of a family.

The activity's explicit rules are the ones about how to use the game and they were basically the same for the 3 phases of the study. After the researchers explained the rules and the activity's object (goal), which were to produce narratives for a children's book, the dynamics began. Usually the player responsible for starting the story showed more difficulties when choosing a card. This fact was reinforced by the post-activity interviews, where the children reported that actually starting the game was harder than finish it because of the variety of options available. That difficulty was so intense that in the second phase of the study, there was a change in the protocol and the cards were positioned face up in four different groups, by categories: objects, scenarios, characters and actions. This was seen as positive by some interviewed children, since by limiting the visual field, the choice of cards seems to become easier.

In the third phase of the study the explicit rule of "writing the stories by a single student" was broken, as some children did not respect the role of the student editor. Some children argued about how the story should be and ended up taking the transcription sheets notes from their colleagues. Another student editor, unsatisfied with the course of the story, stopped writing on the transcription sheets and started to use her lined notebook.

This fact can also be justified due to the peculiarity of the transcription sheets, which have no lines as the ones they are used to use at school. It was also noted that a child who had the editor role was somehow acting as a group leader, perhaps feeling her/himself empowered by the task of writing down the story. The students reported that the action cards helped in the process of constructing the narratives, although the teacher pointed out that the card were often quoted, but not included on the board. Some students also wondered if because of these cards they could only use those specific actions when creating the story. The teachers even suggested a new use for these cards: the definition of themes, for example, the "scare" card would create a horror story, etc. 
In the second phase of the activity, the students already had a better sense of the final objective, so, aspects such as textual coherence, characters uniformity and the notion of the story's beginning, middle and end were well understood and fixed by the children. The teacher reported that she noticed on some of her students a decrease in the usual worry about achieving the "minimum of lines" in the writing classwork, as well as constructing a better notion of the structure beginning, middle and end of a story. This fact may reflect a better alignment between the teacher's objective and the student's objective when working on a writing activity. At the end, the creation of the text became more natural.

In the first and second phase of the study, the community organized itself regarding to the division of labor in a way that researchers recorded the story while the students narrated. In addition, the researchers also had the role of asking questions that could stimulate the development of the plot story when it was needed.

In the third phase the community was organized according to the previous stages: a group of students and the teacher; but there was a change in the division of labor: the students became the editors, replacing the researchers role. It was realized that for the activity to become autonomous and apt to replication in other schools this role change would be of crucial importance, since researchers could not be present in all of the writing activities in different schools. This modification altered some aspects of the activity such as the concept about the writing activity itself. Some of the players kept asking how to write specific words while some misspell the sentences. The teacher took this as an opportunity to work on these grammatical questions.

Finally, the result of the activity in all the three phases was the production of the children's books. One of the concerns faced in this study was that the writing level should be in accordance to the subjects' age, what was confirmed by one of the teachers. One parameter used to evaluate this was a list of elements that according to the teacher should be included in every student writing: (1) Characters and their characteristics (adjectives); (2) Characters' names (nouns); (3) Objects (nouns); (4) Scenarios (local context of the stories); (5) Actions (verbs); (6) Punctuation Marks (dash, question mark, exclamation, etc.); and (7) Text Structural Elements (paragraphs, sentences, etc).

\section{FINAL REMARKS}

The individual and collective analysis of the activity allowed to understand how an information design artifact, in our case the board game and the deck of cards, may contribute to the mediation of the writing activities. The board game, an artifact associated with fun, allows creating a dynamic activity, generating engagement and, thus, facilitating learning. 
The study makes it possible to explore several questions related to language skills development, such as the construction of narratives, including the notion of beginning, middle and end of a story and the idea of time and space. The interpretation of the images of the cards also helps to stimulate the creative and imaginative capacity of the children, besides helping the teacher to notice some social issues, when there is a relation with some external element to the narrative itself. The action of writing the text of the stories in transcription paper sheets, when attributed to the students, also contributes to the writing practice, stimulating the spelling and the capacity of textual representation in itself, in a coherent and objective way.

There is also the possibility of changing the activity system configuration depending on the teacher's objective. For example, it is possible to organize a collective activity with the whole classroom instead of dividing into groups, resulting in a single story.

Despite the advantages and flexibility of using the artifact, some details of the game design and its mechanics may be adjusted in order to enhance the narrative structure and facilitate the use itself. There are some issues that can be verified in future researches: (1) the possibility of reorganizing the graphic line indicating the flow of the narrative on the board to better comprise with the western reading orientation in order to do not confuse the users (fact validated by two teachers); (2) the possibility of inserting specific points on the board to indicate the beginning, middle and end of the story, as well as points of climax among other narrative resources. For this intervention it would be interesting more studies into narrative theories, their elements, procedure and structure; (3) the creation of new cards or a specific rule that would facilitate the connection between them, since it was verified that sometimes the narrative appeared to have blocks of disconnected texts; (4) the development and testing of new transcription paper sheets which may be like lined notebooks, for example, a format widely used in writing exercises at schools.

The Activity Theory made possible to collect and analyze structured data, besides being useful in the schematic representation of the results. The Principle of the Activity Hierarchical Structure, based on the Activity - Action - Operation triad was used in the analysis at the individual level, focusing mainly on the relationship between the subject and the artifact involved. This analytical instrument was the basis for the identification of the 4 Discursive Operations used in the discourse analysis: (1) to narrate using only the figure of the card; (2) to narrate using the figure of the card and another element already present in the narrative; (3) to narrate relating the figure of the card to one or more elements of the imagination; (4) to narrate through the ideas association, without mentioning the figure of the card. For future researches, it might be important to name each category 
aiming at summarizing their meaning in an objective way. In addition, the concept of discursive operations may be deeply explored, e.g. relating them to the Vygotsky's ideas about the role of speech in planning actions, when oriented to solving problems.

On the other hand, the Engeström's Diagram of the Activity System (1987) proved useful in mapping the components involved and their connections, as well as identifying changes in the system when changing one of them, as has happened when there was a change in the division of labor and some students began to write the text of the stories while others narrated; or when it changed some specific dynamic about the artifact usage, such as how to start the game; or even when issues related to the artifact itself were altered, such as the change in the design of the board's path or the insertion of the action cards.

The research had some difficulties due to the teacher and school's narrow schedule, which have many pedagogical activities and obligations to the Municipal Secretary of Education. The context of the field research, being as authentic as possible without researchers controlling the environment, generates a necessity to adapt to the reality and objectives of the subjects involved. For this reason, the whole dynamics of the activities and the objectives were previously aligned with the teachers involved, so the research could be aligned with the pedagogical objectives of the school.

This research analyzed the contribution and impact of an artifact (board game and deck of cards) for the creation of narrative writing in the context of elementary school. However, the research protocol and its artifacts, besides the two analytical instruments from the Activity Theory may be used for future studies, in a similar context and with a larger audience. The group Atividades de Leitura nas Escolas (Reading Activities at Schools), in which the research is inserted, continues to develop other studies, such as the whole process to create a children's book, including the graphic representation of the stories and the final publishing of the books, exploring other skills with the children and exploring other kinds of learning.

\section{REFERENCES}

Bonsiepe, G. (2011). Design, cultura e sociedade. São Paulo, SP: Blucher.

Coutinho, S. G., \& Lopes, M. T. (2011). Design para educação: uma possível contribuição para o ensino fundamental brasileiro. O Papel social do design gráfico: história, conceitos \& atuação profissional. São Paulo, SP: SENAC.

Engeström, Y. (1987). Learning by Expanding: An Activity - Theoretical Approach to Developmental Research. Helsinki: Orienta-Konsultit.

Eisner, W. (2005). Narrativas gráficas. São Paulo, SP: Devir. 
Gamba, N. G. J. (2013). Design de Histórias 1: O Trágico e o Projetual no Estudo da Narrativa. Rio de Janeiro, RJ: Rio Books.

Gancho, C. V. (2002). Como Analisar Narrativas. Série Princípios. São Paulo, SP: Ática.

Kaptelinin, V. (2013, September 18). Activity Theory. In The Encyclopedia of Human-Computer Interaction. Aarhus, Denmark: The Interaction Design Foundation. Retrieved from http://www.interactiondesign.org/encyclopedia/activity_theory.html.

Kaptelinin, V., \& Nardi, B. (2006). Acting with Technology: Activity Theory and Interaction Design. Cambridge, MA: MIT Press.

Kuutti, K. (1996). Activity Theory as a Potential Framework for Human Computer Interaction Research. In Nardi, B (Ed.) Context and consciousness: Activity Theory and Human-Computer Interaction. Cambridge, MA: MIT Press.

Leont'ev, A. N. (1981). Problems of the Development of the Mind. Moscow: Progress.

Reis, C., \& Lopes, A. C. M. (1988). Dicionário de teoria da narrativa. São Paulo, SP: Ática.

Wertsch, J. V. (1991). Voices of the mind: A sociocultural approach to mediated action. Cambridge, MA: Harvard University Press. 
